\title{
Mechanism of right thoracic adolescent idiopathic scoliosis at risk for progression; a unifying pathway of development by normal growth and imbalance
}

\author{
Christian Wong
}

\begin{abstract}
Adolescent idiopathic scoliosis is regarded as a multifactorial disease and none of the many suggested causal etiologies have yet prevailed. I will suggest that adolescent idiopathic scoliosis has one common denominator, namely that initial curve development is mediated through one common normal physiological pathway of thoracic rotational instability. This is a consequence of gender specific natural growth of the passive structural components of thoracic spinal tissues for the adolescent female. This causes an unbalanced mechanical situation, which progresses if the paravertebral muscles cannot maintain spinal alignment. The alteration in the coronal plane with the lateral curve deformity is an uncoupling effect due to a culmination of a secondary, temporary sagittal plane thoracic flattening and of a primary, temporary transverse plane rotational instability for the adolescent female. Treatment of adolescent idiopathic scoliosis should address this physiological pathway and the overall treatment strategy is early intervention with strengthening of thoracic rotational stability for small curve adolescent idiopathic scoliosis.
\end{abstract}

\section{Introduction}

Adolescent idiopathic scoliosis has been described as early as $400 \mathrm{BC}$ by Hippocrates [1]. Since then, numerous studies have been conducted to clarify the etiologies behind adolescent idiopathic scoliosis, suggesting a broad variety of causes: central nervous system-related as a result of cortical brain development or disharmony in development between the somatic and autonomic nervous system, growth-related due to anterior spinal overgrowth or asymmetric rib growth, genetic as recognized from twin studies, hormonal related to melatonin, calmodulin or leptin system dysfunction, biomechanical as a result of a medullary or ligamental mechanical tether, related to asymmetry in pre-existing rotational patterns or developmental changes in the trunk, and many others causal theories [2-16]. The mosaic of these theories are now being brought together into a more coherent framework such as the double neuro-osseous theory and a multimodal causal treatment may emerge in the future $[17,18]$. Still, so far no single causal theory for adolescent idiopathic scoliosis has prevailed and it is still a

\footnotetext{
Correspondence: cwon0002@regionh.dk
} Fuglevadvej, 2800 Kgs, Lyngby, Denmark conundrum and regarded as a multifactorial disease $[2,3,18]$. However, the enigma of the common clinical characteristics of adolescent idiopathic scoliosis with a right primary thoracic curve at risk of progression (AIS), developing in the adolescent girl during spinal growth, cry out for a unifying theory, clarifying these aspects, or as formulated by Weinstein; "the key question of how and why initial small curve develops have not been answered" $[2,3,19,20]$. This paper will suggest that AIS should not be explained by one unifying causal theory. The etiology, being by nature multifactorial, is initiated and mediated, however, through one common physiological mechanism of thoracic rotational instability (RI) in turn being a consequence of gender specific natural growth, causing an unbalanced mechanical situation. I will suggest that it is a common physiological pathway of the normal spinal growing tissue bring about or mediates the 'etiologies' of the progressive structural AIS, and it is the 'mediating culprit' that should be addressed when treating. The foundation for this physiological pathway has already been paved thoroughly in the scientific literature, but has to be seen in a pediatric view of growth with the biomechanical perspective of spinal 
instability in regards to treatment. Rather than considering it to be a coherent etiology accounting for all gender, age and curve variations, it should be seen as relevant observations leading to a suggested physiological pathway for scoliosis with a right primary thoracic curve, since treatment of these are required due to risk for progression [20]. Principally, such a common pathway to AIS should answer the following questions; why does AIS develop in adolescent girls? Why is the right thoracic main curve with rotation at risk of progression? And how to stop it?

\section{Hypothesis}

Firstly, AIS seems to be uniquely human and have been attributed to the reclined erect posture of human bipedalism $[3,19,21]$. Secondly, early AIS is almost equally common in both genders, but the incidence and risk of progression increase for girls when reaching the growth spurt $[2,20,22]$. Thirdly, it seems, that the adolescent female (AF) with AIS is taller, but does not differ with respect to a faster growth velocity and maturation rate as believed earlier $[3,22,23]$. These circumstances imply that AIS is not due to abnormal growth but rather a consequence of normal development for the upright modern human and due to gender-related differences [19]. Changes during growth of supporting structural tissue of the spinal bones, ligaments, and muscles for the AF would therefore seem important for the initiation and development of AIS.

In principle, AIS has developed as a consequence of the spine growing into a mechanically unstable column and seems to progress in a self-sustaining 'vicious cycle' due to the effect of gravity and asymmetric loads in a growth-modulating buckling-like manner $[3,19,24]$. Principles of mechanical engineering or column stability tell us, that when a column structure is higher, as in the growing spine, it is less stable and would require stronger inherent constraints for stability $[19,25]$. The spinal growth spurt for both sexes coincides with adolescence, but AF distinguish themselves from males by a significantly increased and with an earlier thoracic growth, and developing 'sexual dimorphism' of slender vertebra $[23,26,27]$. The factors of thoracic growth, slender vertebrae, and reclined posture make the thoracic spine susceptible to rotational instability when subjected to the axial load of gravity - especially when subjected to dorsal shear loads as for humans $[3,21,27,28]$. These factors coincide with the development of a temporarily 'straighter' back in sagittal plane of the thoracic spine, creating a 'lordotic spinal posture' with a smaller thoracic kyphosis at the vertebral growth peak for the $\mathrm{AF}$ as observed by Adams as early as in 1882 [3,21,22,24,28-31]. This might be initiated in the thoracolumbar junction [12] or as a consequence of growth-induced changes in the lumbar lordosis, sacral slope and pelvic incidence [32], but it contributes to the overall RI, since it redirects the axial load of gravity dorsally onto the apices of the transversely heart-shaped thoracic vertebrae with 'biplanar' asymmetry $[19,28,29]$. The thoracic vertebrae will then perform a lateral bending when rotating, due to the 'coupled motion' between the thoracic vertebrae [33]. This mechanism interconnects rotation and lateral bending motion, whilst forcing the posterior element towards the concavity of the AIS $[19,21,29,33-36]$. The alteration in the coronal plane is therefore an uncoupling effect due to a culmination of a secondary sagittal plane deformity and of a primary transverse plane RI for the AF. The concept of axial rotational imbalance is not novel and has already been recognized as a key factor for AIS development $[37,38]$. The changed dorsal-directed load would affect the posterior elements of the facets and costovertebral joints [28]. This makes the thoracic frontally-oriented facet joints susceptible to RI $[28,39,40]$. The thoracic spine will follow the preexisting rotational pattern to the right, since the normal adolescent also has a right superior facet asymmetry [3,39-41]. Moreover, when the costovertebral joints' mechanical integrity is compromised, it would seem to accentuate rotation of the vertebrae and subsequently the 'coupled motion' of lateral bending [42]. Yet another 'coupled motion' seems to occur, in which rotation of the vertebrae subsequently lead costae to rotate, thus probably facilitating the 'hump' $[35,43]$. Moreover, the thoracic cage increases in size during this period of spinal growth, whilst displaying truncal asymmetry and a relative narrowing for the $\mathrm{AF}$, adding to the instability $[12,44]$.

Changes in flexibility of the passive structures of spinal soft tissue including ligaments and discs occur for the normal AF. Spinal mobility develops with a significant increase in thoracic rotation to the right in adolescence, otherwise becoming stiffer in the thoracic spine in all other planes for the AF $[41,45,46]$. Lumbar lateral flexion also increases with a shift from left to right and the spine develops significantly less overall anterior flexion for the AF $[41,47,48]$. These gender-related changes in flexibility favor RI by developing a mechanical situation of increased lumbar lateral flexion and right thoracic rotation for the AF without the ability to compensate for the latter by flexing forward thoracically in the sagittal plane [19]. These factors force the spine into the classic shape of AIS under the aforementioned 'right' circumstances of increased growth, increased flexibility, and 'lordotic' posture, which peaks for girls in early adolescence. Not surprisingly the spine regains rotational stability as the AIS curve develops and progresses $[49,50]$.

Already half a century ago muscle imbalance was suggested as causation for AIS [3,19,51,52]. Differences in paravertebral muscle morphology, electromyographic response, and behavioral response to exercise have indicated 
that muscle imbalance is a cause for progression or regression of AIS [2,3,52-55]. The majority of AIS remain stable, but the rest either regress or progress [52]. This has led to a muscle balancing/tuning theory, where the spinal muscles - in a heightened state - try to return the spine to a neutral position, displaying a 'wavy' curve pattern with fluctuations in lateral curve shape in mild and early AIS when followed closely $[20,22,52]$. The paravertebral muscles are suggested to have a correcting function, trying to straighten the thoracic spine as a compensatory mechanism to the increasing instability. The compensatory role of the paravertebral muscles is substantiated by the partial straightening of the spinal column of AIS during nighttime using electric muscle stimulation [56]. However, AIS progresses when the paravertebral muscles fail to compensate and stabilize for the inherently rotationally unstable thoracic spine $[3,19,29]$.

The many aforementioned proposed etiological factors contribute to the instability, thus disturbing the spinal equilibrium and trigger initiation of AIS through the proposed physiological pathway. The anatomical variation, and the multiple and variable destabilizing factors give rise to the morphological variation in AIS curves. Morphological changes in spinal bone would seem to be an adaptive response and secondary to the initial thoracic rotational instability $[29,40]$.

In conclusion, the obvious lateral spinal curvature in the coronal plane is a consequence rather than the cause of AIS, but "by the time the AIS achieve clinical significance, it is the secondary deformity which is obvious and masks or obscures the underlying primary deformity" [29]. Moreover, there is a physiological pathway for development of the classic right thoracic curve of AIS for AF, and this is right thoracic rotational instability. This described pathway should be addressed when treating AIS.

\section{Treatment}

In the last decades the nature of treating the clubfoot has been changed successfully by Ignatius Ponseti, where his first article was hypothetical by nature as this one, and to paraphrase his 'concluding words' [57]:

"We are handicapped because of our ignorance of the primary causes of the deformity of AIS...The altered form of the lateral curvature is the result rather than the cause of the deformity... and the essence of this deformity of the spine consists in the twisting of the thoracic spine due to rotational instability by a temporary development of thoracic hypokyphosis...Treatment entails correction of the position of the thoracic sagittal curvature as well as the stretching of thoracic ligaments and strengthening rotational thoracic and lumbar muscles. The younger the girl, the easier these corrections are. Success requires a thorough knowledge of the deformity and of the functional anatomy of the spine".
I will suggest that treatment of primary right thoracic idiopathic scoliosis should address the physiological pathway, namely by early identification and treatment of small curve AIS, strengthening thoracic rotational stability by exercise and creating an external hyperkyphosing thoracic posture by light bracing or by other means of sagittal plane hyperkyphotic and coronal plane central autocorrection. Rotational strengthening exercises should apply appropriate parts of the principles of targeted training with focus specifically on trunk control of the chest $[17,58]$. Earlier brace intervention than that which is presently practiced has recently been examined, and the strategy of early intervention is somewhat substantiated [59]. Likewise, brace treatment focusing on sagittal plane correction by thoracolumbar junction hyperlordosation have shown both initial and short-term promising results of coronal plane correction $[60,61]$, and autocorrective training, which would address the central nervous systeminduced asymmetric spinal development, have also been recognized as an effective treatment $[17,62]$. The perspective of treating the underlying etiological factors are attractive, but do not seem eminent, hence treatment aimed at this proposed physiological pathway of AIS would (almost readily) be feasible. However, Proof of validity of the proposed physiological pathway and treatment are interrelated and will first arise after implementation of treatment and documentation of a shift in the natural history of AIS. Large prospective longitudinal intervention studies with randomization to either the current regime or my proposed treatment would be needed [2].

The efficacy of the current conservative treatment of bracing have been questioned [63,64], and it has been claimed that omitting bracing is inconsequential [65] It has nevertheless been prescribed for half a century [66]. Recently, bracing has been rigorously tested scientifically, and it seems to minimize the risk of progression for AIS in respect of the threshold for surgery [67]. However, it is still being questioned in spite of this meticulous scientific effort [68]. Moreover, bracing is physically and emotionally strenuous for the AF with a correspondingly low compliance [69-71]. From this point of view, it would seem inappropriate not to look for alternate treatment strategies [72].

In conclusion, in this study I have suggested a physiological mechanism that gives a comprehensive explanation to the enigmas of AIS. It lies inherently in the nature of this developmental disease that long-term systematic scientific proof is needed to confirm the predictions. However, this is written to inspire future AIS research.

\section{Competing interests}

The author declares that he has no competing interests.

Received: 3 November 2014 Accepted: 16 January 2015 Published online: 27 January 2015 


\section{References}

1. Vasiliadis ES, Grivas TB, Kaspiris A. Historical overview of spinal deformities in ancient Greece. Scoliosis. 2009;4(6):1-13.

2. Weinstein SL, Dolan LA, Cheng JC, Danielsson A, Morcuende JA. Adolescent idiopathic scoliosis. Lancet. 2008;371(9623):1527-37.

3. Kouwenhoven JW, Castelein RM. The pathogenesis of adolescent idiopathic scoliosis: review of the literature. Spine (Phila Pa 1976). 2008;33(26):2898-908.

4. Tang NL, Yeung HY, Hung WW, Liao CD, Lam TP, Yeung HM, et al. Genetic epidemiology and heritability of AIS: a study of 415 Chinese female patients. J Orthop Res. 2012;30(9):1464-9.

5. Wang D, Shi L, Chu WC, Burwell RG, Cheng JC, Ahuja AT. Abnormal cerebral cortical thinning pattern in adolescent girls with idiopathic scoliosis. Neuroimage. 2012;59(2):935-42.

6. Chu WC, Lam WW, Chan YL, Ng BK, Lam TP, Lee KM, et al. Relative shortening and functional tethering of spinal cord in adolescent idiopathic scoliosis? study with multiplanar reformat magnetic resonance imaging and somatosensory evoked potential. Spine. 2006;31(1):E19-25.

7. Geissele AE, Kransdorf MJ, Geyer CA, Jelinek JS, Van Dam BE. Magnetic resonance imaging of the brain stem in adolescent idiopathic scoliosis. Spine. 1991;16(7):98-63.

8. Lowe T, Lawellin D, Smith D, Price C, Haher T, Merola A, et al. Platelet calmodulin levels in adolescent idiopathic scoliosis. Do the levels correlate with curve progression and severity ? Spine. 2002;27:768-75.

9. Qiu Y, Sun X, Qiu X, Li W, Zhu Z, Zhu F, et al. Decreased circulating leptin level and its association with body and bone mass in girls with adolescent idiopathic scoliosis. Spine. 2007;32(24):2703-10.

10. Moreau A, Wang DS, Forget S, Azeddine B, Angeloni D, Fraschini F, et al. Melatonin signaling dysfunction in adolescent idiopathic scoliosis. Spine. 2004;29(16):1772-81.

11. Grivas TB, Burwell RG, Purdue M, Webb JK, Moulton A. A segmental analysis of thoracic shape in chest radiographs of children. Changes related to spinal level, age, sex, side and significance for lung growth and scoliosis. J Anat. 1991;178:21-38

12. Cheung KM, Wang T, Hu YG, Leong JC. Primary thoracolumbar scoliosis in pinealectomized chickens. Spine. 2003;28(22):2499-504.

13. Sevastik JA. Dysfunction of the autonomic nerve system (ANS) in the aetiopathogenesis of adolescent idiopathic scoliosis. Stud Health Technol Inform. 2002;88:20-3.

14. Guo X, Chau WW, Chan YL, Cheng JC. Relative anterior spinal overgrowth in adolescent idiopathic scoliosis. Results of disproportionate endochondralmembranous bone growth. J Bone Joint Surg (Br). 2003;85(7):1026-31.

15. Castelein RM. Pre-existent rotation of the normal spine at different ages and its consequences for the scoliotic mechanism. Stud Health Technol Inform. 2012;176:20-5

16. van der Plaats A, Veldhuizen AG, Verkerke GJ. Numerical simulation of asymmetrically altered growth as initiation mechanism of scoliosis. Ann Biomed Eng. 2007:35(7):1206-15.

17. Burwell RG, Aujla RK, Grevitt MP, Dangerfield PH, Moulton A, Randell TL, et al. Pathogenesis of adolescent idiopathic scoliosis in girls - a double neuro-osseous theory involving disharmony between two nervous systems, somatic and autonomic expressed in the spine and trunk: possible dependency on sympathetic nervous system and hormones with implications for medical therapy. Scoliosis. 2009:4:24.

18. Burwell RG, Dangerfield PH, Moulton A, Grivas TB, Cheng JC. Whither the etiopathogenesis (and scoliogeny) of adolescent idiopathic scoliosis? Incorporating presentations on scoliogeny at the 2012 IRSSD and SRS meetings. Scoliosis. 2013;8(1):4.

19. Millner PA, Dickson RA. Idiopathic scoliosis: biomechanics and biology. Eur Spine J. 1996;5(6):362-73.

20. Soucacos PN, Zacharis K, Gelalis J, Soultanis K, Kalos N, Beris A, et al Assessment of curve progression in idiopathic scoliosis. Eur Spine J. 1998;7(4):270-7.

21. Machida M, Saito M, Dubousset J, Yamada T, Kimura J, Shibasaki K. Pathological mechanism of idiopathic scoliosis: experimental scoliosis in pinealectomized rats. Eur Spine J. 2005;14(9):843-8.

22. Archer IA, Dickson RA. Stature and idiopathic scoliosis. A prospective study J Bone Joint Surg Br. 1985;67(2):185-8.

23. Veldhuizen $A G$, Baas $P$, Webb PJ. Observations on the growth of the adolescent spine. J Bone Joint Surg (Br). 1986;68(5):724-8.

24. Stokes IA. Analysis and simulation of progressive adolescent scoliosis by biomechanical growth modulation. Eur Spine J. 2007;16(10):1621-8.
25. Timoshenko SP, Gere MP. Elastic buckling of bars and frames. In Timoshenko SP (ed) Theory of Elastic Stability, $2^{\text {nd }}$ edn. publisher Mcgraw Hill; 1961. pp 46-8.

26. Taylor JR, Twomey LT. Sexual dimorphism in human vertebral body shape. J Anat. 1984;138:281-6.

27. Meijer GJ1, Homminga J, Hekman EE, Veldhuizen AG, Verkerke GJ. The effect of three-dimensional geometrical changes during adolescent growth on the biomechanics of a spinal motion segment. J Biomech. 2010;43(8):1590-7.

28. Kouwenhoven JW, Smit TH, van der Veen AJ, Kingma I, van Dieën JH, Castelein RM. Effects of dorsal versus ventral shear loads on the rotational stability of the thoracic spine: a biomechanical porcine and human cadaveric study. Spine (Phila Pa 1976). 2007;32(23):2545-50.

29. Dickson RA, Lawton JO, Archer IA, Butt WP. The pathogenesis of idiopathic scoliosis. Biplanar spinal asymmetry J Bone Joint Surg Br. 1984;66(1):8-15.

30. Poussa MS, Heliövaara MM, Seitsamo JT, Könönen MH, Hurmerinta KA, Nissinen MJ. Development of spinal posture in a cohort of children from the age of 11 to 22 years. Eur Spine J. 2005;14(8):738-42.

31. Adams W. Lectures on the pathology and treatment of lateral and other forms of curvature of the spine. London: Churchill; 1882.

32. Mac-Thiong JM, Berthonnaud E, Dimar 2nd JR, Betz RR, Labelle H. Sagittal alignment of the spine and pelvis during growth. Spine. 2004;29(15):1642-7.

33. Panjabi MM, Brand RA, White AA. Mechanical properties of the human thoracic spine as shown by three-dimensional load-displacement curves. J Bone Joint Surg Am. 1976;58(5):642-52.

34. White 3rd AA. Kinematics of the normal spine as related to scoliosis. J Biomech. 1971;4(5):405-11.

35. Lee D. Biomechanics of the thorax: a clinical model of the in vivo function. J manual \& manipulative Ther. 1993;1(1):13-21.

36. Sizer PS, Brismée JM, Cook C. Coupling behavior of the thoracic spine: a systematic review of the literature. J Manipulative Physiol Ther. 2007;30(5):390-9.

37. Roaf R. Rotation movements of the spine with special reference to scoliosis. J Bone Joint Surg (Br). 1958;40-B(2):312-32

38. Burwell RG, Cole AA, Cook TA, Grivas TB, Kiel AW, Moulton A, et al. Pathogenesis of idiopathic scoliosis. The Nottingham concept Acta Orthop Belg. 1992;58 Suppl 1:33-58.

39. Masharawi $Y$, Rothschild B, Dar G, Peleg S, Robinson D, Been E, et al. Facet orientation in the thoracolumbar spine: three-dimensional anatomic and biomechanical analysis. Spine (Phila Pa 1976). 2004;29(16):1755-63.

40. Masharawi YM, Peleg S, Albert HB, Dar G, Steingberg N, Medlej B, et al. Facet asymmetry in normal vertebral growth: characterization and etiologic theory of scoliosis. Spine (Phila Pa 1976). 2008;33(8):898-902.

41. Janssen MM, Kouwenhoven JW, Schlösser TP, Viergever MA, Bartels LW, Castelein RM, et al. Analysis of preexistent vertebral rotation in the normal infantile, juvenile, and adolescent spine. Spine (Phila Pa 1976). 2011;36(7):E486-91.

42. Little JP, Adam CJ. Effects of surgical joint destabilization on load sharing between ligamentous structures in the thoracic spine: a finite element investigation. Clin Biomech (Bristol, Avon). 2011;26(9):895-903.

43. Appelt K. Rib movements of the monosegmental specimen. In: Appelt K, editor. Biomechanics of the thoracic spine: development of a method to measure the influence of the rib cage on thoracic spine movement. 1st ed. Ulm Germany: Universität Ulm Medizinische Fakultät; 2013. p. 41-5.

44. DiMeglio A, Canavese F, Charles YP. Growth and adolescent idiopathic scoliosis: when and how much? J Pediatr Orthop. 2011;31(1):S28-35.

45. Mellin G, Poussa M. Spinal mobility and posture in 8- to 16-year-old children. J Orthop Res. 1992;10(2):211-6.

46. Mellin G, Härkönen $H$, Poussa M. Spinal mobility and posture and their correlations with growth velocity in structurally normal boys and girls aged 13 to 14. Spine (Phila Pa 1976). 1988;13(2):152-4.

47. Moran HM, Hall MA, Barr A, Ansell BM. Spinal mobility in the adolescent. Rheumatol Rehabil. 1979;18(3):181-5.

48. Haley SM, Tada WL, Carmichael EM. Spinal mobility in young children. A normative study. Phys Ther. 1986;66(11):1697-703.

49. Poussa M, Mellin G. Spinal mobility and posture in adolescent idiopathic scoliosis at three stages of curve magnitude. Spine (Phila Pa 1976). 1992;17(7):757-60.

50. Poussa M, Härkönen H, Mellin G. Spinal mobility in adolescent girls with idiopathic scoliosis and in structurally normal controls. Spine (Phila Pa 1976). 1989;14(2):217-9. 
51. Riddle HF, Roaf R. Muscle imbalance in the causation of scoliosis. Lancet. 1955;268(6877):1245-7.

52. Modi HN, Suh SW, Yang JH, Hong JY, Venkatesh K, Muzaffar N. Spontaneous regression of curve in immature idiopathic scoliosis - does spinal column play a role to balance? An observation with literature review. J Orthop Surg Res. 2010:5(80):1-8.

53. Cheung J, Veldhuizen AG, Halberts JP, Sluiter WJ, Van Horn JR. Geometric and electromyographic assessments in the evaluation of curve progression in idiopathic scoliosis. Spine (Phila Pa 1976). 2006;31(3):322-9.

54. Kim H, Lee CK, Yeom JS, Lee JH, Cho JH, Shin SI, et al. Asymmetry of the cross-sectional area of paravertebral and psoas muscle in patients with degenerative scoliosis. Eur Spine J. 2013;22(6):1332-8.

55. Smidt GL, Blanpied PR, White RW. Exploration of mechanical and electromyographic responses of trunk muscles to high-intensity resistive exercise. Spine (Phila Pa 1976). 1989;14(8):815-30.

56. Axelgaard J. Transcutaneous electrical muscle stimulation for the treatment of progressive spinal curvature deformities. Int Rehabil Med. 1984;6(1):31-46.

57. Ponseti IV, Campos J. Observations on pathogenesis and treatment of congenital clubfoot. Clin Orthop Relat Res. 1972;84:50-60.

58. Butler PB. A preliminary report on the effectiveness of trunk targeting in achieving independent sitting balance in children with cerebral palsy. Clin Rehabil. 1998;12(4):281-93.

59. Wiemann JM, Shah SA, Price CT. Nighttime bracing versus observation for early adolescent idiopathic scoliosis. J Pediatr Orthop. 2014;34(6):603-6.

60. van Loon PJ1, Kühbauch BA, Thunnissen FB. Forced lordosis on the thoracolumbar junction can correct coronal plane deformity in adolescents with double major curve pattern idiopathic scoliosis. Spine. 2008;33(7):797-801.

61. van Loon PJ, Roukens M, Thunnissen FB, Munneke J. A similar approach in bracing of adolescent scoliosis and kyphosis with the use of growth itself in thoracolumbar lordotic intervention (TLI). Stud Health Technol Inform. 2012;176:68-72.

62. Fusco C, Zaina F, Atanasio S, Romano M, Negrini A, Negrini S. Physical exercises in the treatment of adolescent idiopathic scoliosis: an updated systematic review. Physiother Theory Pract. 2011;27(1):80-114.

63. Negrini S, Minozzi S, Bettany-Saltikov J, Zaina F, Chockalingam N, Grivas TB, et al. Braces for idiopathic scoliosis in adolescents. Cochrane Database Syst Rev. 2010;1, CD006850.

64. Davies $E$, Norvell D, Hermsmeyer J. Efficacy of bracing versus observation in the treatment of idiopathic scoliosis. Evid Based Spine Care J. 2011:2(2):25-34

65. Goldberg CJ, Moore DP, Fogarty EE, Dowling FE. Adolescent idiopathic scoliosis: the effect of brace treatment on the incidence of surgery. Spine (Phila Pa 1976). 2001;26(1):42-7.

66. Blount WP, Schmidt AC, Bidwell RG. Making the Milwaukee brace. J Bone Joint Surg Am. 1958;40-A(3):526-8.

67. Weinstein SL, Dolan LA, Wright JG, Dobbs MB. Effects of bracing in adolescents with idiopathic scoliosis. N Engl J Med. 2013;369(16):1512-21.

68. Dolan LA, Wright JG, Weinstein SL. Effects of bracing in adolescents with idiopathic scoliosis. N Engl J Med. 2014;370(7):681.

69. Reichel D, Schanz J. Developmental psychological aspects of scoliosis treatment. Pediatr Rehabil. 2003;6(3-4):221-5.

70. Bunnell WP. Nonoperative treatment of spinal deformity: the case for observation. Instr Course Lect. 1985;34:106-9.

71. Chan SL, Cheung KM, Luk KD, Wong KW, Wong MS. A correlation study between in-brace correction, compliance to spinal orthosis and health-related quality of life of patients with adolescent idiopathic scoliosis. Scoliosis. 2014;9(1):1. doi:10.1186/1748-7161-9-1.

72. Goldberg CJ, Moore DP, Fogarty EE, Dowling FE. Scoliosis: a review. Pediatr Surg Int. 2008;24(2):129-44.

\section{Submit your next manuscript to BioMed Central and take full advantage of:}

- Convenient online submission

- Thorough peer review

- No space constraints or color figure charges

- Immediate publication on acceptance

- Inclusion in PubMed, CAS, Scopus and Google Scholar

- Research which is freely available for redistribution

Submit your manuscript at www.biomedcentral.com/submit 